\title{
Políticas públicas para o desenvolvimento local atrelado às atividades de piscicultura no Munícipio de Porto Grande, Estado do Amapá
}

Public policies for local development linked to fish farming activities in the Municipality of Porto Grande, State of Amapá

Políticas públicas para el desarrollo local relacionadas con las actividades de cultivo de peces en el Municipio de Porto Grande, Estado de Amapá

Netiê Izabel da Silva de Oliveira Aluna de Pós-Graduação-PPGMDR, UNIFAP, Brasil netieoliveira@gmail.com

Josiane Pereira Cardoso Aluna de Pós-Graduação-PPGMDR, UNIFAP, Brasil rita.josi@hotmail.com

José Francisco de Carvalho Ferreira Pós-doutorando em Desenvolvimento Regional , UNIFAP, Brasil zfcofer@gmail.com 


\section{RESUMO}

Nos últimos anos, a atividade aquícola vem apresentando picos de desenvolvimento, em resposta a crescente demanda por pescado e seus derivados. A necessidade de implementações de politicas públicas para o sucesso dessa atividade é imprescindível, pois a atividade aquícola é uma alternativa de se recuperar os estoques pesqueiros afetados e de sobrevivência para quaisquer comunidades que se identifique com a criação de peixes. Para que a piscicultura contribua para o desenvolvimento econômico do Estado do Amapá, é necessário que seja construída politicas públicas que atenda a realidade da comunidade e que comporte as possibilidades do Estado. Objetiva-se com este estudo fazer uma abordagem exploratória a fim de identificar o papel das políticas públicas para a atividade de piscicultura atrelado ao desenvolvimento local no Município de Porto Grande. Por ser a piscicultura em Porto Grande uma atividade relativamente nova, existe pouca informação ou dados confiáveis e atuais sobre os tipos de produção, a industrialização e comercialização, o que prejudica o estabelecimento de políticas públicas efetivas.

Palavras-chave: Piscicultura. Politicas públicas. Desenvolvimento local.

Abstract: In recent years, the aquaculture activity is showing development peaks in response to growing demand for fish and fish products. The need for public policy implementation for the success of this activity is essential because the aquaculture activity is an alternative to recover the affected fish stocks and survival for any communities that identify with fish farming. For fish farming contributes to the economic development of the State of Amapá, it must be built public policy that meets the reality of the community and incorporating the state's possibilities. Our objective is to make this study an exploratory approach in order to identify the role of public policy for fish farming activity linked to local development in the municipality of Porto Grande. Being the fish in Porto Grande a relatively new activity, there is little information or reliable and current data on the types of production, manufacturing and marketing, which hinders the establishment of effective public policies.

Keywords: Fish farming. Public policies. Local development.

Resumen: En los últimos años, la actividad acuícola está mostrando picos de desarrollo en respuesta a la creciente demanda de pescado y productos pesqueros. La necesidad de implementación de políticas públicas para el éxito de esta actividad es esencial, ya que la actividad de la acuicultura es una alternativa para recuperar las poblaciones de peces y la supervivencia de las comunidades afectadas que se identifican con la cría de peces. Para el cultivo de peces contribuye al desarrollo económico del Estado de Amapá, debe construirse una política pública que se encuentra con la realidad de la comunidad y la incorporación de las posibilidades del Estado. Nuestro objetivo es hacer de este estudio un enfoque exploratorio con el fin de identificar el papel de la política pública para la actividad de cría de peces relacionada con el desarrollo local en el municipio de Porto Grande. Siendo el pescado en Porto Grande una actividad relativamente nueva, hay poca información o datos fiables y actuales sobre los tipos de producción, fabricación y comercialización, lo que dificulta el establecimiento de políticas públicas eficaces.

Palabras clave: Granja de pescados. Políticas públicas. El desarrollo local. 


\section{INTRODUÇÃO}

A piscicultura é considerada uma atividade muito antiga no mundo, porém no Brasil ela surge em um momento da história em que há grandes declínios no que tange a riqueza dos recursos naturais, o aumento do desmatamento das matas ciliares, o crescimento acelerado da população e consequentemente a competitividade no setor comercial e econômico quanto a exigências de alimentos mais nutritivos e naturais (SILVA, 2011).

Os empreendimentos voltados à piscicultura quando planejados rigorosamente, podem gerar benefícios para o piscicultor, para o desenvolvimento local e posteriormente lucros para o setor econômico em âmbito regional (CASTELLANI; BARRELLA, 2005). Já que a piscicultura é uma atividade rentável e com grande viabilidade de instalação, esta vem sendo desejada por diversas pessoas, por seu valor e promoção de alimento natural. Os peixes advindos de cultivos hoje possuem um nível de consumo elevado pelo mercado consumidor (GAMA, 2008). Nos últimos anos, a aquicultura vem apresentando um grande desenvolvimento, em resposta a crescente demanda por pescado e seus derivados. A exploração de populações selvagens, em geral, já atingiu o seu máximo potencial, particularmente quando nos referirmos às espécies alvos de comercialização, assim a atividade da piscicultura vem crescendo e sua produção aumentando (NOMURA, 2010).

As potencialidades econômicas do Estado do Amapá, já são almejadas desde o período em que nosso estado ainda pertencia ao português Bento Manuel Parente, éramos possuidores de recursos naturais e extrativistas que despertava interesses pertinentes nos holandeses, franceses e ingleses. Localizado na parte Norte do Brasil, o Amapá tem um território de $143.453,7 \mathrm{~km}^{2}$, que corresponde a 1,67\% de toda porção do território nacional. (IBGE, 1998).

O município de Porto Grande, localizado na região centro-leste do estado do Amapá possui condições privilegiadas para o desenvolvimento da piscicultura. O aparecimento desta atividade na região despertou o interesse das comunidades locais. E essa atividade aquícola no município de Porto Grande foi aprovada e pela LEI № 413 de 26 de Junho de 2014, Dispõe sobre a Atividade de Aquicultura no Município de Porto Grande e dá outras Providências.

Apoiado no contexto da discussão sobre as elaborações de políticas públicas para a atividade de piscicultura, este trabalho busca estudo fazer uma abordagem exploratória a fim de identificar o papel das políticas públicas para a atividade de piscicultura atrelada ao desenvolvimento local no Município de Porto Grande.

\section{METOdOLOGIA}

Neste estudo utilizou-se a pesquisa exploratória, em levantamentos bibliográficos e documentais, definido por Marconi e Lakatos, (2007, p.12), como sendo um apanhado geral 
Revista Nacional de

sobre os principais trabalhos já realizados, revestidos de importância por serem capazes de fornecer dados atuais e relevantes relacionados com o tema.

Para a coleta de dados foi realizada através do método descritivo, onde se faz um levantamento bibliográfico, sobre as resoluções ou portarias sancionadas pelo Governo, relacionados à questão ambiental, sobre as politicas públicas voltadas para a atividade aquícola.

Utilizou-se como ferramenta para o estudo, câmera fotográfica, scanner de mão para registro de documentos, internet, computador e o programa ArcGis para a elaboração do mapa da área de estdo.

O município de Porto Grande (Figura 1) tem uma população de 16.809 habitantes (dezesseis mil e oitocentos e nove) possui uma área de $4.402 \mathrm{~km} 2$, uma densidade de 5,3 habitantes por $\mathrm{km}^{2}$, apresentando um clima tropical chuvoso (IBGE, 2010). As áreas de concentração da maioria das pisciculturas instaladas no município de Porto Grande encontram-se em sua região interiorana como na Colônia Agrícola do Matapi, Monguba, Cupixi.

Figura 1: Mapa do Município de Porto Grande-Amapá

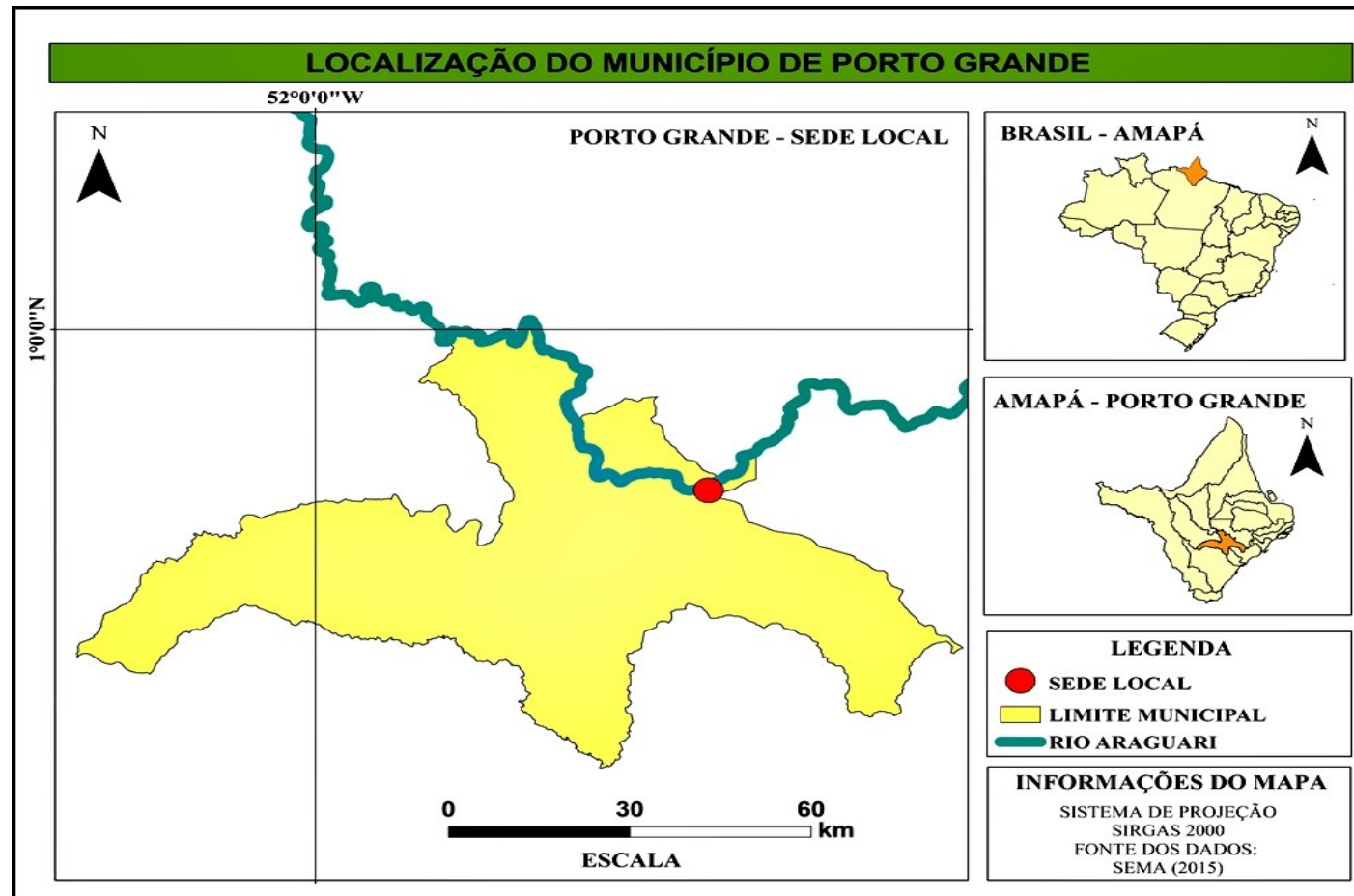

Fonte: Elaborado pelos autores, 2016. 


\section{Politicas públicas e suas autarquias que remetem a atividade da Piscicultura}

O surgimento das politicas públicas no mundo teve quatro grande fundadores que serviram de alicerce para sua implantação são eles: H. Laswell, H. Simon, C. Lindblom e D. Easton. Apesar do desenvolvimento dos significados e funções do termo politicas públicas, ainda hoje, quando se pensa nesse termo, direcionamos nossa concepção diretamente em torno do pressuposto "interesses" políticos (SOUZA, 2006).

As políticas públicas são abrangidas como as de responsabilidade do Estado, quando visadas a questão de implementação e manutenção de seus ideais, porém as tomadas de decisões são idealizadas com a participação de órgãos públicos e componentes da sociedade. Neste sentido, políticas públicas não podem ser reduzidas a políticas estatais (HÖFLING, 2001).

Com a Lei delegada n. 10, correspondente à 11 de outubro de 1962, é criada então uma autarquia chamada de Superintendência para o Desenvolvimento da Pesca, cuja sigla representada por SUDEPE, assim a atividade pesqueira atinge sua fase industrial, passando por institucionalizações que remetem até o ano de 1966. Onde a finalidade da SUDEPE era sempre voltada para o crescimento da produção (OSTRENSKY et al, 2008).

A fim de administrar os recursos pesqueiros disponíveis para desenvolver a atividade de pesca e aquicultura as politicas públicas passaram-se então a ser instituídas através da concessão de incentivos à produção, caracterizando o novo código da Pesca de 1967, através do Decreto-Lei no 221 de 28 de outubro de 1967 (ABDALLAH, 1998).

Em 22 de fevereiro de 1989, a Lei 7.735 elimina a SUDEPE, que foi vinculada ao Instituto Brasileiro de Defesa Florestal (IBDF), e cria o Instituto Brasileiro do Meio Ambiente e dos Recursos Naturais Renováveis (IBAMA) para atender as questões voltadas à pesca e aquicultura, porém a partir desse momento o crescimento da produção de pescado advindo da atividade aquícola, artesanal e ou/industrial não alcança uma produção positiva para o País, tornando-se estagnada (OSTRENSKY et al, 2008).

Em 10 de janeiro de 2003, com a edição da Medida Provisória 103, hoje Lei 10.683, foi criada a Secretaria Especial da Aqüicultura e Pesca - SEAP, com objetivo de atender as necessidades do setor pesqueiro. Em 15 de setembro de 2004 foi criado o CONAPE (Conselho Nacional da Aqüicultura e Pesca), cujo objetivo é desenvolver subsídios para a formulação de políticas públicas voltadas para o setor. (OSTRENSKY et al, 2008).

\subsection{LEGISLAÇÃO PERTINENTE ÀS ATIVIDADES DE PISCICULTURA}

Apesar de a piscicultura ser uma atividade praticada desde a época da colonização, o processo de regulamentação e institucionalização, vem sendo dinamizado recentemente por órgãos governamentais. Essa preocupação recente com a aplicação e desenvolvimento com o setor aquícola fazer jus a ênfase, pois é uma atividade que necessita de uma assistência técnica 
eficaz já que utiliza-se o uso de solo, água, meio ambiente, assim pode-se chegar a conservação de recursos naturais (TIAGO, 2003).

Para Tiago (2003), a falta de consenso entre os atos administrativos normativos que regulamentam o arranjo da atividade aquícola que foram impostos no conjuntos de legislação no Brasil não conseguem suprir todas as demandas do setor aquícola, muitas vezes causando conflitos entre si.

No documento exclusivo da Prefeitura de Porto Grande que aprova a Lei № 413 de 26 de Junho de 2014 em seu Artigo 1o paragrafo único descreve a:

A regularização ambiental será efetuada junto ao órgão ambiental competente, conforme legislação vigente, através de critérios e procedimentos de Licenciamento Ambiental da Aquicultura recomenda para os Estados e Municípios que tenham competência para efetuar o licenciamento ambiental da Aquicultura, exceto em áreas específicas como áreas indígenas, fronteiriças e outros. (Lei № 413/JUNHO/2014, p. 1).

Esta Lei transferiu o poder de Regulamentação ambiental para atividade aquícola do Município de Porto Grande para os órgãos competentes. Estes tem responsabilidade de efetuar os procedimentos legais para os empreendimentos aquícolas através de vários requisitos a serem preenchidos pelos piscicultores e assim obter o licenciamento ambiental.

Destaca Tiago (2003), que para o setor aquícola a obtenção do licenciamento ambiental ainda apresentam muitos problemas, fazendo com que haja a demora nessa autorização pois a falta de instrumentos específicos que amparam o desenvolvimento sustentável da piscicultura ainda é muito recorrente.

\subsubsection{Licenciamento Ambiental para o Estado do Amapá}

A Resolução do CONAMA, correspondente ao no 237/97 é definida a partir de uma serie de fatores importantes à atividade aquícola (importância alimentar, ambiental, econômico e ordenamento) cujo objetivo é estabelecer normas e critérios para o licenciamento da aquicultura, que previne necessidade de ordenamento da atividade aquícola.

Corrêa (2011) afirma que dependendo da abrangência do impacto ambiental os empreendimentos devem ser licenciados em um único nível de competência (Federal, Estadual ou Municipal). No âmbito do Estado do Amapá, compete ao Instituto do Meio Ambiente e de Ordenamento Territorial (IMAP) as ações fiscalizadoras e de licenciamento Ambiental.

A Lei № 413 de 23 de Junho que regulamentaria a atividade aquícola no município de porto Grande, foi aprovada no ano de 2014, com prefeito em exercício Eucias Guimarães Borges. Esta disponibiliza a seguinte afirmação em seu Artigo 10: 
Art. $1^{\circ}$ - As atividades de aquicultura desenvolvidas em tanques escavados, pequenos reservatórios, canais de igarapés, tanques-rede, dentre outras estruturas localizadas em áreas urbanas ou rurais, serão regulamentadas pela presente Lei № 413/JUNHO/2014.

\subsection{DESENVOLVIMENTO ECONÔMICO E O ESTADO DO AMAPÁ}

No mesmo período em que há a criação de estados-nações, surge o aprimoramento das práticas comerciais, que tem seu desenvolvimento sincrônico a economia, esta economia inicialmente tinha perspectiva moldadas no pensamento filosófico (BATISTA, 2012).

A complexidade que a economia vinha assumindo com o passar dos anos era inerente às relações estabelecidas dentro das diferentes comunidades, acarretando num fluxo de produções que por vezes se cruzavam a culturas diferentes, onde havia a mistura de produções resultantes de diferentes costumes socioeconômicos (SOUZA, 1999).

Adam Smith é o principal percursor do surgimento da economia como ciência (1723-1790), considerado o pai da Economia Política. Para Smith a economia era caracterizada como uma ampliação consecutiva na qual o mercado tem a possibilidade de expansão através de novos assalariados produtivos e a produtividade desses trabalhadores é relacionada diretamente ao acumulo de capital e para David Ricardo, considerado um discípulo de Adam Smith o aumento do custo de vida repercute-se sobre a expansão dos salários industriais, reduzindo a taxa média de lucro do conjunto da economia (SOUZA, 1999).

Thomas Malthus representou o padrão de uma visão que desconhece os benefícios da industrialização ou do progresso tecnológico, Para ele, a diferença entre as classes sociais era uma consequência inevitável. (HENRIQUES, 2007). John Stuart Mil preocupava-se muito impacto moral da industrialização, pois os pilares de desenvolvimento ou seja a divisão de trabalho levaram a uma insensibilização espiritual e moral (HEYDT, 2014). Para Jean Baptiste Say, o valor dos bens era formado por todos os recursos utilizados em sua produção (BATISTA, 2012).

Observou-se até então uma abordagem do ponto de vista econômico, relacionado aos principais teóricos da economia clássica, a partir dessa analise, podemos fazer um levantamento sobre a percepção da economia no estado do Amapá.

A economia do Amapá é diretamente dependente dos recursos naturais caracterizando-se pela exploração de matérias-primas, produtos primários e semi-elaborados.

O Estado do Amapá, bem como os outros estados componentes da região norte no transcorrer dos anos, principalmente a partir da década de 70 vem sendo propendido pelas politicas publicas desenvolvimentistas. 


\subsubsection{Desenvolvimento local e Piscicultura no Município de Porto Grande}

O caráter mais humano vem sendo uma das principais características quando se manifesta a ideia de planejamento de desenvolvimento, pois o ser humano deve ser visto não apenas como favorecido no processo de desenvolvimento, mas também como um agente desse processo. Esse desenvolvimento local vem ocupando estratégias de planejamento e ação que seja compartilhado por iniciativas da própria população (MARTINS, 2002).

E a atividade aquícola no Brasil ainda é praticada geralmente por produtores rurais, apesar desse cenário esta mudando aos poucos, mas o que ainda prevalece é são os produtores rurais como principais piscicultores e geralmente são de pequena e média escala de produção (OSTRENSKY; BOEGER, 1998).

E em relação as politicas públicas, a comunidade em que se esta sendo trabalhado o desenvolvimento local, desta deve participar diretamente nas formulações de políticas públicas desenvolvidas para seus municípios, pois elas devem estar cientes dos impactos e benefícios dessas politicas desenvolvidas no município (BUCCl, 2001).

\section{RESULTADOS}

\subsection{ECONOMIA NO ESTADO DO AMAPÁ}

A economia em âmbito regional vem se adaptando de acordo com a realidade em que ela se encontra, pois desde os tempos considerados hoje para nós mais remotos ela já era praticada, e vem se moldando de acordo com as necessidades humanas. E é isso que acontece nos países que se encontram em desenvolvimento.

A pesar de nosso Estado esta se desenvolvendo, o dinamismo econômico, a contribuição tecnológica, os elos com as empresas e governo federal ainda não viabilizou a consolidação expansiva no setor econômico. Esse fato verificar-se quando se compara a economia do estado do Amapá com os demais estados.

\subsection{DESENVOLVIMENTO DA ATIVIDADE AQUÍCOLA NO MUNICÍPIO DE PORTO GRANDE}

No processo de desenvolvimento econômico a atividade aquícola desempenha um papel crucial quando envolvidas na conjuntura de desenvolvimento de uma determinada região. Pois essa atividade propicia uma demanda de mão-de-obra, viabiliza a questão das necessidades nutritivas da população, combatendo diretamente a pobreza em si (LOPES et al, 2010).

A precária assistência técnica no município de Porto Grande é um dos principais problemas para o desenvolvimento das pisciculturas, porém este problema pode ser resolvido a partir do momento em que as politicas públicas envolvidas com o desenvolvimento da atividade aquícola, ingressarem em eficácia. 


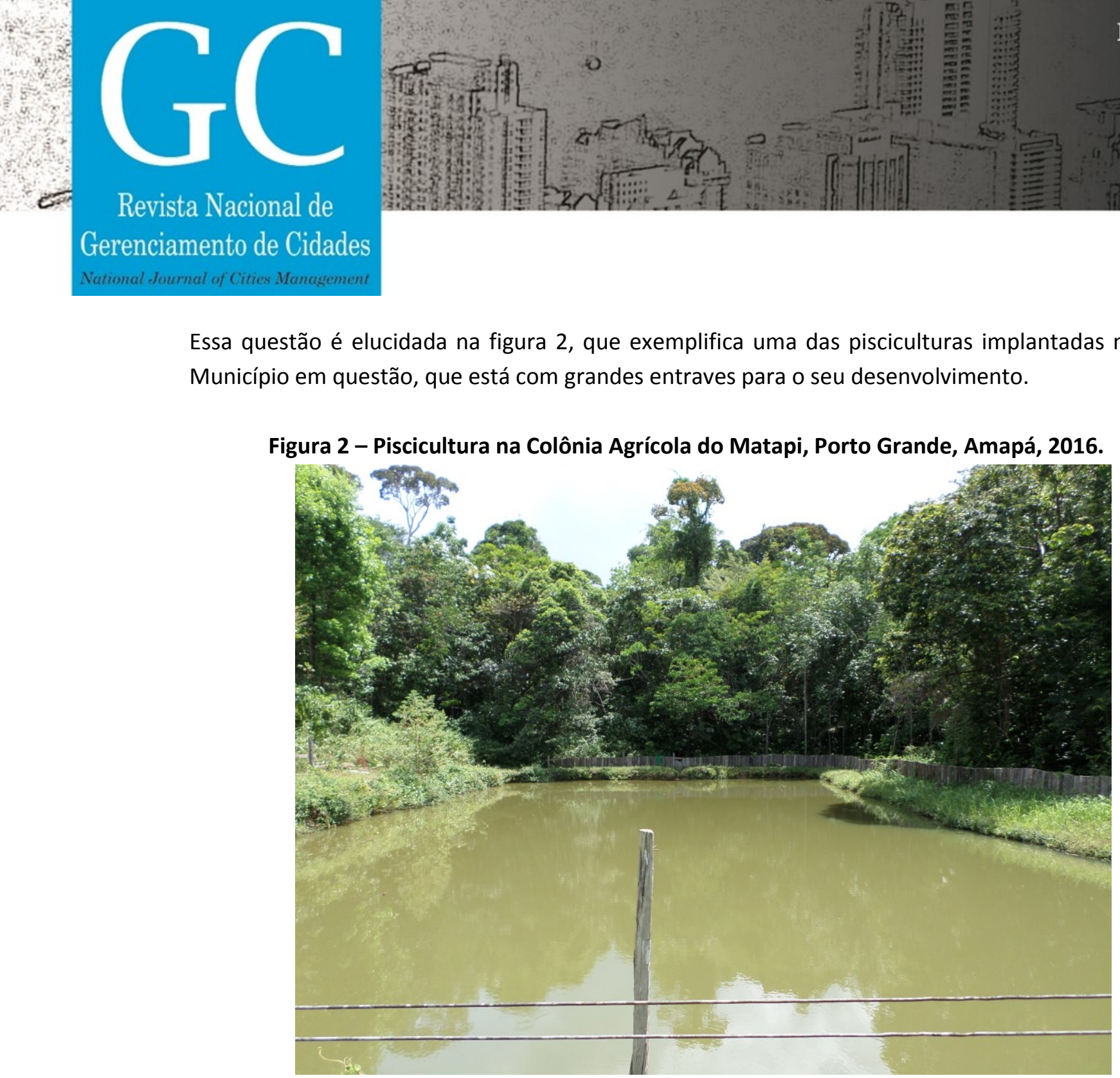

Essa questão é elucidada na figura 2, que exemplifica uma das pisciculturas implantadas no Município em questão, que está com grandes entraves para o seu desenvolvimento.

Fonte: Netiê Oliveira.

\subsection{DESENVOLVIMENTO LOCAL E SUAS PREMISSAS}

No município de Porto Grande, as pisciculturas existentes em sua maioria são piscicultura familiar, onde a família trabalha diretamente do empreendimento para obter o sustento, estes trabalham em conjunto, dividindo funções e todos são beneficiados, por ser uma atividade aquícola familiar, é necessário que as politicas públicas sejam voltadas diretamente à este âmbito familiar.

Para Rozas (1998), desenvolvimento local é a organização comunitária em torno de um planejamento para o desenvolvimento:

Por uma perspectiva de construção social, constituindo assim em um instrumento fundamental, de caráter orientador e condutor, de superação da pobreza. Não se trata, contudo, de buscar tão somente o atendimento às carências materiais, mas a identificação e a promoção das qualidades, capacidades e competências existentes na comunidade e no lugar'. (ROZAS, 1998, p.8). 
Assim o desenvolvimento local no município de Porto Grande deve articulado tendo como agente de transformação os moradores desse município, pois eles são a identidade do local, as premissas e funcionalidades do desenvolvimento devem ser geradas a partir do consenso da comunidade, visto que os ideais a serem atingido vão refletirem na competência dos moradores de Porto Grande, pois o desenvolvimento local não visa só a questão econômica, ele prioriza as competências e habilidades dos moradores envolvidos.

\section{CONCLUSÃO}

O desenvolvimento econômico regional no Estado do Amapá é visto a partir do andamento do crescimento esporádico da competitividade seja entre as pequenas e ou grandes empresas que são induzidas ao melhoramento de seu produto e internalização. E essas discussões acerca de desenvolvimento econômico e regional do Amapá evidencia que ainda há uma fragilidade nesse setor, esse gargalo é potencializado pelas desarticulações no setor econômico.

Assim, a postura a ser assumida pelo Estado deverá contemplar as necessidades do ambiente econômico empresarial visando politicas públicas para seu crescimento. Uma alternativa plausível para alavancar essa deficiência seria dentro do processo de planejamento e desenvolvimento econômico local mudar a realidade de que o homem como ser holístico passasse a ser considerado não apenas um beneficiário do desenvolvimento, porem simultaneamente seja visto como o sujeito desse desenvolvimento, essa é uma tendência de caráter que parte de um pressuposto de que somos autores responsáveis pelo nosso crescimento.

Assim atividade de piscicultura no Estado do Amapá ainda é incipiente, porque ainda não garantiu um lugar de proeminência no setor econômico, devido as fragilidades que o estado ainda apresenta, porém seu desempenho tecnológico e a aceitação do mercado consumidor instiga o surgimento de novos empreendimentos no setor aquícola, esse panorama vai se desenvolvendo de acordo com o surgimento desses empreendimentos e assim fazendo com que essa atividade seja crucial no desenvolvimento econômico do Estado do Amapá.

Por ser a piscicultura em Porto Grande uma atividade relativamente nova, existe pouca informação ou dados confiáveis e atuais sobre os tipos de produção, a industrialização e comercialização, o que prejudica o estabelecimento de políticas públicas efetivas. Porto Grande apresenta uma linha de tendência na concentração de pequenos e médios empreendimentos no que tange as atividades de piscicultura.

A percepção da fluidez das atividades bem como os gargalos para o bom funcionamento local são relevantes para o seu desenvolvimento em nível local e regional.

A partir deste levantamento de informações expostas neste artigo, poderemos contribuir futuramente com o Município através da execução de um diagnóstico da atividade aquícola no município de Porto Grande, Estado do Amapá, como subsídio ao desenvolvimento LOCAL. Que já é proposta da dissertação da primeira autoria deste artigo. 


\section{REFERÊNCIAS BIBLIOGRÁFICAS}

ABDALLAH, P. R. 1998. Atividade pesqueira no Brasil: política e evolução. Piracicaba. 137 p. Tese (Doutorado em Economia Aplicada) - Escola Superior de Agricultura Luiz de Queiroz/USP, São Paulo.

BATISTA, João Marcos. A Evolução Da Economia: Uma Abordagem Histórica Sobre Os Principais Modelos, Teorias E Pensadores. 2012.

BUCCI, Maria Paula Dallari et alli. Direitos humanos e políticas públicas. São Paulo, Pólis, 2001. 60p. (Cadernos Pólis, 2)

CASTELLANI, D., Barrella, W. Caracterização da Piscicultura na região do Vale de Ribeira-SP. Ciênc. agrotec., Lavras, v. 29, n. 1, p. 168-176, jan./fev. 2005.

CORRÊA, J. M. Analise Critica do Licenciamento Ambiental da Piscicultura no Estado do Amapá. 2011. 49 f. Monografia (TCC em Administração e Legislação Pesqueira) - Coordenação do Curso de Engenharia de Pesca, Universidade do Estado do Amapá-UEAP.

GAMA, C. de S. A criação de tilápia no estado do Amapá como fonte de risco ambiental. Acta Amazônica. vol. 38(3) 2008: 525 - 530.

HENRIQUES, Abel. THOMAS ROBERT MALTHUS: A Teoria Malthusiana. Instituto Politécnico de Coimbra. Instituto Superior De Engenharia De Coimbra 2007.

HEYDT, Colin. Tradução: John Stuart Mill (1806-1873). Faculdade Católica de Pouso Alegre, 2014.

HOFLING, ELOISA DE MATTOS. Estado e Políticas (Públicas) Sociais. Cadernos Cedes, ano XXI, no 55, novembro/2001

INSTITUTO BRASILEIRO DE GEOGRAFIA E ESTATíSTICA (IBGE). XII Senso Demográfico 2010. Disponível em: http//www.ibge.gov.br/censo. Acesso em 01/07/2016.

LOPES, Maria Lucia Bahia et al. Mercado e dinâmica espacial da cadeia produtiva da pesca e aquicultura na Amazônia. Pará. 2010. 51 p.

MARCONI, Marina de Andrade; LAKATOS, Eva Maria. Fundamentos de metodologia científica. São Paulo: Atlas, 2007.

MARTINS, S. R. O. Desenvolvimento Local: questões conceituais e metodológicas. Revista Internacional de Desenvolvimento Local. Vol. 3, N. 5, Set. 2002.

NOMURA, Ichiro. O futuro da pesca e da aquicultura marinha no mundo. Ciências do Mar/Artigos. P. 28-32. 2010.

OSTRENSKY, A.; BORGHETTI, J. R.; SOTO, D. Aqüicultura no Brasil: o desafio é crescer. - Brasília, 2008. 276 p. : il. 
Revista Nacional de

Gerenciamento de Cidades

National Journal of Cities Management

ROZAS, G. Pobreza y desarrollo local. In: Excerpta, Universidade do Chile, n. 7, 1998. (Na Internet: http// rehue.csociales.uchile.cl)

SILVA, L. S. da. A importância das associações e cooperativas para o fortalecimento da piscicultura na agricultura familiar no Estado da Bahia. IX ENCONTRO NACIONAL DA ECOECO. Outubro de 2011.

Brasília - DF - Brasil.

SOUZA, Celina. Políticas Públicas: uma revisão da literatura. Sociologias, Porto Alegre, ano $8, \mathrm{n}=16$, jul/dez 2006, p. 20-45

SOUZA, Nali de Jesus. Desenvolvimento Econômico. 4 ed., São Paulo : Atlas, 1999.

TIAGO, G. G. Aqüicultura, Meio Ambiente e Legislação. 2003. Disponível: <http://www.pesca.sp.gov.br/noticia.php?id not=13>. Acesso: 08/16/2016. 